\title{
OBITUARY
}

\section{Martin Marivate}

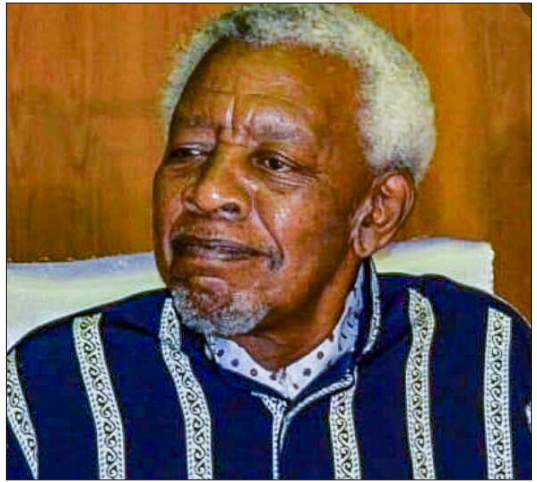

I write this tribute to a gentle giant under whom I served as a student registrar and consultant at King Edward VIII Hospital at the then University of Natal.

Martin Marivate hailed from an illustrious family from Valdezia in Northern Limpopo. His father was the first Xitsonga novelist, and his late eldest brother Charles, who was among the first batch of graduates of the University of Natal in 1958, went on to become a well-known physician. Later, another brother, the late Russell Marivate, also graduated from the Medical School and practised as a doctor in Soshanguve and Winterveldt. Martin Marivate enrolled at the University of Natal in the late 1950s, qualifying as a doctor in the early 1960s.

The University of Natal Medical School was the brainchild of medical missionaries Drs John McCord and Alan Taylor, whose lobbying with the apartheid government as far back as 1921 was finally successful in 1951. During their student years, the Marivate brothers were among those who bore the brunt of the inhumane apartheid policies to which the newly formed Medical School had to adhere. Some of these were poor living facilities at Alan Taylor Residence in Wentworth, not being allowed to become a member of the allwhite University Athletic Union or to wear the white University blazer, and seating for parents at the graduation ceremonies always being at the back of the hall.
In spite of qualifying with a medical degree, the new graduates found themselves further degraded by the discriminatory policies of the Nationalist government. The salary scale for newly qualified doctors was based on racial lines, with black doctors receiving the lowest salary. In addition, the environment of the tertiary hospital of the University was poor and it lacked up-to-date facilities, unlike the other medical schools.

The young Martin Marivate overcame these difficult circumstances and became part of the main workforce in the Department of Obstetrics and Gynaecology and maternity section at King Edward VIII Hospital. It was not unusual for the hospital to have deliveries of approximately 22000 babies per annum. The smell of the iJuba factory across from the labour ward permeated through the atmosphere into the labour ward, and the medical staff had to contend with this while performing their duties.

The work overload and the lack of postgraduate training facilities for blacks made it difficult to pursue a higher degree. After completing his internship, Dr Marivate remained in the Department of Obstetrics and Gynaecology, where he initially worked as a medical officer and registrar under Prof. Derk Crichton, the first head of the Department, and later as a senior consultant and principal specialist under Prof. Hugh Philpott, who became the second head in 1974.

On the academic front, Martin Marivate's clinical skills and knowledge of practical obstetrics were outstanding. He mentored and tutored his students and registrars with passion. He was always immaculately dressed and softly spoken, and his humility and humble personality endeared him to all his colleagues and made him easily accessible to his students. His main research in obstetrics and gynaecology was on multiple pregnancy, especially twin pregnancy. He published several papers in well-known international journals on this subject with colleagues from Australia and the UK, and also contributed to the literature on obstetrics in the developing world. His research findings are still quoted in articles on this subject. He was deputy head of the Department for several years and served as acting head for a period from 1984 . In 1991 he was transferred to the Medical University of Southern Africa (Medunsa), where he served as head of department until his retirement in 2000 .

As a form of relaxation from the hectic schedule of the labour ward he was instrumental in forming a tennis club in the department, of which he was regarded as the 'chairman'. He was often referred to as 'Chairman' and not Prof. Marivate, and this became a household name at King Edward VIII Hospital and in the Department of Obstetrics and Gynaecology. He was passionate about tennis. On a lighter note, a senior colleague recently remarked that if a doctor applied for a registrar post and had tennis skills, this added to his chances of being given a post!

Having recently read about Prof. Marivate's family and their academic achievements, I am sure that below his humility and humbleness there was a sense of pride. The degrees that the Marivate clan have achieved are so numerous that they were regarded by a reputable magazine as one of the cleverest families in South Africa.

We are proud of you, Prof. Marivate, for walking in the path you did and making such significant contributions to the specialty of obstetrics and gynaecology. To your wife Maud, five children (Makhanani, Basani, Khensani, Nana and Fana), fourteen grandchildren and three great-grandchildren, we extend our deepest sympathies. Their loss is our loss.

May your gentle soul rest in peace.

Hamba kahle!

\section{Siva Moodley}

Durban Obstetrics and Gynaecological Society and Honorary Lecturer, Department of Obstetrics and Gynaecology, University of KwaZulu-Natal, Durban, South Africa siva@ispace.co.za 